tain of these have often been placed in separate families largely on the basis of the presence or absence of the pygidial plate. This character is regarded as being unreliable since it is often lost in very different bees.

\section{Glossary of Communicable Diseases}

A LIST of terms in the main European languages and in Latin denoting the various communicable diseases has recently been published ("Lexique Polyglotte des Maladies Contagieuses" (Polyglot Glossary of Communicable Diseases). By Dr. Yves Biraud. (London: Allen and Unwin: League of Nations Publications Dept., 1944. Pp. 354. 4s.). The author states in his introduction that circumstances did not allow of the sending of questionnaires to medical authorities of the various countries or of submitting proofs of the Glossary to them. This is quite obvious, and anyone looking for an accurate guide of this type will be well advised to await the appearance of a heavily amended second edition.

The term communicable is very widely interpreted, and the lists include appendicitis and Ludwig's angina, osteomyelitis and pemphigus of unspecified type. Catarrhal jaundice is listed twice, although this probably erroneous term for infective hepatitis is now nearly obsolete. Herpes zoster and herpes febrilis are given as synonyms. Chancroid, the most specific and commonly accepted name for soft chancre, does not appear. In the section on syphilis the terms for various manifestations do not correspond in the columns for the different languages.

\section{Sulphadiazine Treatment of Meningitis}

According to the U.S. Office of the Surgeon General, a saving of 90 out of 100 soldiers from death by meningitis has been achieved by sulphadiazine. The death-rate from meningitis in the U.S. Army in the present War is less than 3 per cent, whereas it was $\mathbf{9 3 . 2}$ per cent in the Revolutionary and Civil Wars and $39 \cdot 2$ per cent in the War of 1914-18. According to the U.S. Army Commission on Meningitis, as little as two grams of sulphadiazine will banish the germs from the nose and throat of most persons for a period of several weeks.

\section{Pole Treatment}

IN an article on ground-line treatment of standing poles (Bell Lab. Rec., 22, No. 11; July 1944), C. H. Amadon discusses the preservative method developed by Bell System engineers. External deterioration of an untreated pole in service begins in the ground section with infection by wood-destroying fungi which, once established, continue there unless adverse conditions are imposed, as for example, by the application of a suitable wood preservative. Two general classes of preservatives might be used for ground-line treatment, (1) oily materials such as creosote, and (2) water solutions of toxic salts such as zinc chloride and sodium fluoride. Sodium fluoride is particularly good for penetrating the heartwood of cedar and chestnut timbers, but it is not permanent. Creosote or creosote and coal tar, although not as penetrating as the water-soluble salt, is as lasting as any preservative known.

Beginning in 1935, Bell Laboratories engineers treated experimentally a total of 428 poles and posts with coal-tar creosote and other coal tar products, sodium fluoride, sodium silico-fluoride, and proprietary pastes and solutions containing preservative compounds. Periodic examinations and accumulated evidence during five years showed that treatment at the ground line with sodium fluoride and a mixture of creosote and coal tar is highly effective. This treatment effectively reduces the rate of deterioration of poles in line, and their service life (ground line condition) will be increased by about six years. This is sufficient to justify the costs involved, but an additional saving accrues from the possibility of placing pole line inspection on a six-year instead of the usual three-year cycle. The cumulative result of the ground-line treatment is a reduction in labour and expense of pole line maintenance-inspection and in the need for new poles.

\section{Paint Drying by Radiant Heat}

Imperial Chemical INdUstries, LTd., has recently issued a handy twenty-page booklet on this subject for the purpose of providing information on the properties of radiant heat, to indicate how these apply to the different types of plant now available for stoving paints, and how the qualities of the paints used are affected by the process. The chapter contents of the booklet relate to heat transfer, radiant heat, methods of drying paint, radiant heating equipment, radiant heating technique, and paints and radiant heat. Copies of the booklet may be obtained, free of charge, from I.C.I., Ltd., Belmont, The Ridgeway, Mill Hill, London, N.W.7.

\section{Seismology in Chins}

IT is learned (Earthq' ake Notes, 15, Nos. 3 and 4 ; 1944) that the active recording of earthquakes is being continued in China. The Japanese invasion caused the National Geological Survey of China to change its headquarters to Chungking. The seismograph station at Chiufeng had to be abandoned. Dr. $\mathrm{S}$. P. Lee has re-established the seismological work at Pehpei near Chungking. He has built a onecomponent instrument (north-south), which is being operated with a period of $4.5 \mathrm{sec}$. Recording began in October 1943.

\section{University of Bristol}

THE following appointments in the University of Bristol have recently been announced:

Dr. J. E. Harris, to be professor of zoology in succession to Prof. C. M. Yonge, who has been appointed Regius professor of zoology in the University of Glasgow.

Dr. Wilson Baker, to be Alfred Copper Pass professor of chemistry in succession to Prof. E. L. Hirst, who has been appointed professor of chemistry in the University of Manchester.

Dr. A. G. Pugsley, to be professor of civil engineering in succession to Prof. J. F. Baker, who is now professor of mechanical sciences in the University of Cambridge.

Erratum.-Sachchidananda Banerjee writes, in connexion with his communication "Effect of Vitamin $\mathrm{C}$ on the Adrenaline Content of the Adrenal Glands of Guinea Pigs" in Nature of April 29, p. 526, the phrase "The adrenal glands were extracted with trichloracetic acid for adrenaline and ascorbic acid according to the method of Rees"' should read: "The adrenal glands were extracted with trichloracetic acid for adrenaline and ascorbic acid according to the method of Barker and Marrian ${ }^{2}$. The adrenaline was estimated chemically by the method of Rees". 